\title{
CARACTERÍSTICAS FÍSICAS E ACÚMULO DE NUTRIENTES PELOS CACHOS DE 'NIAGARA ROSADA' EM VINHEDOS NA REGIÃO DE JUNDIAII'
}

\author{
MARCO ANTONIO TECCHIO², ERASMO JOSÉ PAIOLI-PIRES ${ }^{3}$, MAURILO MONTEIRO TERRA 3 , \\ LUIZ ANTONIO JUNQUEIRA TEIXEIRA ${ }^{3}$, SARITA LEONEL ${ }^{4}$
}

RESUMO- Este trabalho teve por objetivo realizar um levantamento em 40 vinhedos de 'Niagara Rosada' nos municípios de Jundiaí e Louveira-SP, sendo metade sobre o porta-enxerto 'Ripária do Traviú' e outra sobre o 'IAC 766'. Determinaram-se, em cada vinhedo, a produtividade, a duração do ciclo, o número de cachos e de ramos produtivos por planta, as características físicas dos cachos e bagas, e o acúmulo de nutrientes pelos cachos. Avaliaram-se nos cachos amostrados a massa da matéria fresca, o comprimento e a largura dos cachos e baga, e diâmetro do pedicelo. Os cachos de cada vinhedo amostrado foram secos em estufa e posteriormente submetidos à análise química para determinar os teores de macro e micronutrientes, visando a estimar o acúmulo de nutrientes por tonelada de uva. Constatou-se um comportamento semelhante entre os porta-enxertos para os dados de produtividade, duração do ciclo, número de cachos e ramos produtivos, sendo de, respectivamente, $11.100 \mathrm{~kg} \mathrm{ha}^{-1}, 134$ dias, 13 cachos e 9 ramos produtivos. Quanto às características físicas, os valores médios da massa da matéria fresca, comprimento e largura dos cachos foram de, respectivamente, 209g, 12 e 6,8cm; massa da matéria fresca, comprimento e largura das bagas, e diâmetro do pedicelo de, respectivamente, 4,3g; 19,9; 18,2 e 3,2mm. Quanto ao acúmulo de nutrientes, concluiu-se que a cultivar Niagara Rosada enxertada sobre 'Ripária do Traviú' apresentou maior acúmulo de $\mathrm{P}$, Fe e Zn, enquanto sobre o porta-enxerto 'IAC 766' houve maior acúmulo de Mn. Em ambos os porta-enxertos, a 'Niagara Rosada' apresentou a seguinte escala de acúmulo de nutrientes em ordem decrescente: $\mathrm{K}>\mathrm{N}>\mathrm{P}>\mathrm{Ca}>\mathrm{S}>\mathrm{Mg}>\mathrm{B}>\mathrm{Fe}>\mathrm{Mn}>\mathrm{Cu}>\mathrm{Zn}$.

Termos para indexação: Vitis, uva, nutrição mineral, levantamento nutricional.

\section{PHISICAL CHARACTERISTICS AND ACCUMULATION OF NUTRIENTS BY 'NIAGARA ROSADA' GRAPE CLUSTERS IN JUNIDAÍ REGION GRAPEVINE VINEYARDS}

\begin{abstract}
This research had as purpose to study the physical characteristics and nutrients accumulation in 40 grapevine vineyards of 'Niagara Rosada' cultivar in Jundiaí and Louveira region. Half of the plants was grafted on the rootstock 'Riparia of Traviú' and the other was grafted on the rootstock 'IAC 766'. It were evaluated in each grapevine orchard: yield, cycle stages, clusters number, fertilized stems number per plant, physical characteristics per clusters and berries and accumulation of nutrients by the clusters. In the clusters sampled were evaluated the fresh matter weight, length and diameter of clusters, berries and pedicel. The clusters of each grapevine orchard sampled were dried and evaluated for the nutrients contents, with a purpose to obtain the accumulation of nutrients by metric ton of grape. The results showed similar characteristics between the rootstocks for the yield and cycle duration, clusters number and fertilized stems, being respectively of: $11.100 \mathrm{~kg} \mathrm{ha}^{-1}, 134$ days, 13 clusters and 9 fertilized stems. The physical characteristics showed the following values: $209 \mathrm{~g}$ of fresh matter weight, $12 \mathrm{~cm}$ of length and $6,8 \mathrm{~cm}$ of clusters diameter; 4,3g, 19,9, 18,2 and 3,2mm of fresh matter weight, length, berries and pedicel diameter, respectively. The accumulation of nutrients can concluded that 'Niagara Rosada' cultivar grafted at 'Riparia of Traviú' showed the higher accumulation of P, Fe and Zn, while these cultivar was grafted at 'IAC 766' rootstock there was higher accumulation of $\mathrm{Mn}$. In the both rootstocks, the 'Niagara Rosada' showed the following accumulation of nutrients in decreased order: $\mathrm{K}>\mathrm{N}>\mathrm{P}>\mathrm{Ca}>\mathrm{S}>\mathrm{Mg}>\mathrm{B}>\mathrm{Fe}>\mathrm{Mn}>\mathrm{Cu}>\mathrm{Zn}$.
\end{abstract}

Index Terms: Vitis, grape, nutrients diagnosis and mineral nutrition.

\section{INTRODUÇÃO}

O Estado de São Paulo destaca-se como o maior produtor nacional de uva para mesa, com aproximadamente 39 milhões de plantas e produção de 189,7 mil toneladas. Dentre as cultivares de uva comum para mesa, destaca-se a 'Niagara Rosada', que representa $89,1 \%$ do total de plantas e $49,1 \%$ da produção de uva no Estado. Na Região Leste do estado de São Paulo, a Regional
Agrícola de Campinas representa 66,8\% da produção de 'Niagara Rosada' do Estado, destacando-se os municípios de Jundiai e Louveira (Instituto de Economia Agrícola, 2006).

Segundo levantamento realizado por Ghilardi \& Maia (2001), a produção de 'Niagara Rosada' no município de Jundiaí está localizada em pequenas propriedades, com área entre $5 \mathrm{e}$ 12ha, sendo conduzida em espaldeira, com 3 a 4 fios de arame, e densidade média de 5.000 a 6.000 plantas por hectare. A vida útil

\footnotetext{
(Trabalho 013-07). Recebido em: 03-01-2007. Aceito para publicação em: 20-07-2007.

2 Pesquisador Científico, Centro Avançado de Pesquisa Tecnológica do Agronegócio de Frutas - Instituto Agronômico de Campinas - $13214-820$ - JundiaíSP. tecchio@iac.sp.gov.br.

${ }^{3}$ Pesquisador Científico, Instituto Agronômico de Campinas, C.P. 28.13001-970 Campinas-SP. Bolsista do CNPq. ejppires@iac.sp.gov.br; mmterra@iac.sp.gov.br; teixeira@iac.sp.gov.br

${ }^{4}$ Prof. Dr. Departamento de Produção Vegetal/Área Horticultura FCA- UNESP- Caixa Postal 237 - 18603-970 Botucatu - SP. sarinel@fca.unesp.br
}

Rev. Bras. Frutic., Jaboticabal - SP, v. 29, n. 3, p. 621-625, Dezembro 2007 
da planta é de 15 anos após a formação, com produtividade média de $15.000 \mathrm{~kg} \mathrm{planta}^{-1}$ a partir da $2^{\mathrm{a}}$ colheita. A colheita é realizada geralmente nos meses de dezembro a fevereiro, porém os preços mais elevados têm sido registrados em setembro-outubro e marçoabril.

Como em outras regiões vitícolas, o uso de porta-enxertos na região é prática obrigatória, devido à presença da filoxera (Daktylosphaera vitifoliae, Fitch). Braga (1988) sugeriu para a região de Jundiaí a utilização dos porta-enxertos 'Ripária do Traviú' e 'IAC 766'. Sabe-se que os porta-enxertos apresentam variação em vigor, em conseqüência das diferentes exigências nutricionais e capacidade de absorção de água e nutrientes, influenciando na produtividade e nas características físicas dos cachos da videira.

Pauletto et al. (2001a), em Taubaté-SP, avaliaram a produção e o vigor de 'Niagara Rosada' sobre cinco porta-enxertos. As maiores produtividades médias foram obtidas quando se utilizaram os porta-enxertos 'IAC 313', 'IAC 766', e 'Ripária do Traviú', sendo de, respectivamente, $8.960,8.630$ e $6.630 \mathrm{~kg} \mathrm{ha}^{-1}$. Com os porta-enxertos 'Kober 5BB' e 'Schwarzmann', obtiveram, respectivamente, 4.130 e $3.960 \mathrm{~kg} \mathrm{ha}^{-1}$. À exceção do porta-enxerto 'Kober 5BB', os demais apresentaram comportamento semelhante quanto ao número de cachos, que foram de 24,2 a 34,6 cachos planta $^{-1}$. Em relação à qualidade dos frutos, Pauletto et al. (2001b) constataram que as videiras enxertadas sobre os porta-enxertos 'IAC 313', 'IAC 766' e 'Ripária do Traviú' apresentaram cachos com comprimento, largura, massa do cacho e número de bagas significativamente maiores do que os verificados nas plantas enxertadas sobre o Kober 5BB e 'Schwarzmann'. A baga apresentou massa significativamente maior no 'IAC 766' e no 'Ripária do Traviú'. Em relação ao ciclo da cultivar Niagara Rosada, Pedro Júnior et al. (1993) avaliaram durante as safras agrícolas 1989-1990 e 1990-1991, os dados fenológicos da planta para as épocas de poda de $15-07,1^{\circ}$.- $08,15-08$ e $1^{\circ}$.- -09 . Concluíram que o ciclo total da cultura na região de Jundiaí variou de 130 a 159 dias, em função da data de poda, com a duração do ciclo diminuindo, progressivamente, da primeira para a última época de poda.

Além da influência do porta-enxerto na produção e qualidade dos cachos, o aspecto nutricional da cultura é outro fator de fundamental importância. Nesse aspecto, verificou-se que poucos produtores da região realizam análise de solo, utilizando inadequadamente os corretivos e fertilizantes, ocasionando dessa maneira desequilíbrios nutricionais, o que acarreta queda na produção e na qualidade dos frutos (Tecchio 2005). Albuquerque (1996) e Fráguas \& Silva (1998) mencionaram que desequilíbrios nos vinhedos são freqüentes, principalmente nos teores de nitrogênio, cálcio, magnésio e potássio. Em função da queda em rentabilidade da cultura, mencionado pelos produtores da região, têm-se procurado adequar as técnicas de cultivo visando à redução nos custos de produção. Dentre essas técnicas, a adubação merece atenção especial, visto que os gastos com calagem e adubação na 'Niagara Rosada' são responsáveis por $23 \%$ do custo de produção (Ghilardi \& Maia, 2001) e a produção de frutos é diretamente influenciada pelo estado nutricional das plantas. Análises de solo e folhas são técnicas que contribuem para a aplicação balanceada de nutrientes mediante a adubação. Além desses aspectos, o conhecimento da acúmulo de nutrientes pelos cachos também é importante para a racionalização da adubação. A quantidade de nutrientes extraídas pela videira é influenciada por vários fatores, dentre os quais as variações na copa e nos porta-enxertos utilizados.

Santos Neto (1973) relatou que, para a produção de 3,0kg planta ${ }^{-1}$ de uva 'Niagara Rosada' enxertada sobre 'Ripária do Traviú', a quantidade acumulada de nutrientes/frutos durante um ciclo de produção foi de 4,6g de N; $2,43 \mathrm{~g}$ de $\mathrm{P} ; 13$, $8 \mathrm{~g}$ de $\mathrm{K} ; 2,8 \mathrm{~g}$ de Ca; 1,86g de Mg. Dechen (1979) verificou que, para a produção de 239,11g de massa seca de cachos por planta, a quantidade de macro e micronutrientes acumulados pelos cachos da cultivar Niagara Rosada, foi de: 2,8g de N; 1,1 de P; 7,5g de K; 0,39g de Ca; $0,19 \mathrm{~g}$ de $\mathrm{Mg} ; 0,32 \mathrm{~g}$ de $\mathrm{S} ; 6 \mathrm{mg}$ de $\mathrm{B} ; 2 \mathrm{mg}$ de $\mathrm{Cu} ; 17 \mathrm{mg}$ de Fe; $35 \mathrm{mg}$ de $\mathrm{Mn}$ e $3 \mathrm{mg}$ de $\mathrm{Zn}$. O acúmulo total de nutrientes, em ordem decrescente, foi: $\mathrm{K}>\mathrm{N}>\mathrm{P}>\mathrm{Ca}>\mathrm{S}>\mathrm{Mg}>\mathrm{Mn}>\mathrm{Fe}>\mathrm{B}>\mathrm{Zn}>\mathrm{Cu}$. Hiroce et al. (1979) determinaram, que para produzir uma tonelada de uva 'Niagara Rosada', são extraídos do solo $879 \mathrm{~g}$ de N; 292g de P; $1890 \mathrm{~g}$ de $\mathrm{K} ; 95 \mathrm{~g}$ de $\mathrm{Ca} ; 95 \mathrm{~g}$ de $\mathrm{Mg} ; 173 \mathrm{~g}$ de $\mathrm{S} ; 2,1 \mathrm{~g}$ de B; $8 \mathrm{~g} \mathrm{de} \mathrm{Cl}$; 0,6g de $\mathrm{Cu}, 3,0 \mathrm{~g}$ de Fe, 2,5g de Mn, 3,0mg de Mo e 0,5g de Zn. Verificaram que a ordem decrescente de acúmulo foi $\mathrm{K}>\mathrm{N}>\mathrm{P}>\mathrm{S}>$ $\mathrm{Ca}=\mathrm{Mg}>\mathrm{Cl}>\mathrm{Fe}>\mathrm{Mn}>\mathrm{B}>\mathrm{Cu}>\mathrm{Zn}>\mathrm{Mo}$.

Este trabalho teve por objetivo realizar um levantamento nutricional em vinhedos, nos municípios de Jundiaí e Louveira, visando a avaliar a influência dos porta-enxertos 'IAC 766' e 'Riparia do Traviú' nas características físicas dos cachos e no acúmulo de nutrientes pelos cachos da videira 'Niagara Rosada'. Objetivou-se, também, obter subsídios para a adubação de manutenção dos vinhedos, tomando-se por base a acúmulo de nutrientes pelos cachos de uva.

\section{MATERIAL E MÉTODOS}

O experimento foi realizado em vinhedos comerciais localizados nos municípios de Jundiaí e Louveira-SP, situados a $23^{\circ} 08^{\prime} \mathrm{S}$ e $46^{\circ} 55^{\prime} \mathrm{O}$, com altitude de $715 \mathrm{~m}$, apresentando médias anuais de $1.400 \mathrm{~mm}$ de precipitação pluviométrica, temperatura média de $19,5^{\circ} \mathrm{C}$ e umidade relativa média do ar de $70,6 \%$. Selecionaram-se 40 vinhedos cujas plantas eram conduzidas no sistema de espaldeira e podadas no sistema de cordão esporonado simples. Dos vinhedos amostrados, metade das plantas estavam enxertadas sobre o porta-enxerto 'Ripária do Traviú' e outra metade sobre o 'IAC 766', sendo o espaçamento médio dos vinhedos selecionados de $1,8 \times 0,9 \mathrm{~m}$.

Avaliou-se a produção dos vinhedos amostrados, obtida por informações do produtor, sendo aferidos esses dados mediante uma estimativa de produção realizada em vinte e cinco plantas representativas de cada vinhedo. Nessas plantas selecionadas, realizaram-se as seguintes avaliações: contagem do número de cachos e ramos produtivos; duração do ciclo, medida da data de poda à colheita; características físicas de cachos e bagas, obtidas mediante amostragem de 15 cachos nas plantas selecionadas, sendo 5 cachos pequenos, 5 médios e 5 grandes. Determinaram-se, nos cachos, as seguintes variáveis: massa da matéria fresca, comprimento e largura dos cachos e bagas, e diâmetro do pedicelo. Para se obter a massa da matéria fresca dos cachos, utilizou-se uma balança semi-analítica, com precisão de 
0,1g; para a obtenção do comprimento e da largura das bagas, e do diâmetro do pedicelo (numa subamostra de 10 bagas por cacho), utilizou-se paquímetro digital; para o comprimento e largura dos cachos, utilizou-se paquímetro de madeira, com precisão de $0,1 \mathrm{~cm}$.

Realizaram-se nos 40 vinhedos, amostragem de solo a 0 $20 \mathrm{~cm}$ de profundidade e amostragem de folha completa na época do pleno florescimento. As características químicas avaliadas nas amostras de solo foram: $\mathrm{pH} \mathrm{em} \mathrm{CaCl}_{2}$, matéria orgânica, $\mathrm{P}, \mathrm{K}, \mathrm{Ca}$, $\mathrm{Mg}, \mathrm{H}+\mathrm{Al}, \mathrm{SB}, \mathrm{CTC}$ e $\mathrm{V} \%$, seguindo os métodos descritos por Raij et al. (2001), e os teores de B, Cu, Zn, Fe e Mn, segundo a metodologia proposta por Camargo et al. (1986). Nas amostras de folhas, avaliaram-se os teores de macro e micronutrientes segundo metodologia descrita por Malavolta et al. (1997).

Para estimar-se o acúmulo de nutrientes, após as medições físicas, os cachos foram separados em bagas e engaços, sendo posteriormente submetidos a uma seqüência de lavagens em: água corrente, água destilada contendo detergente neutro a $1 \mathrm{~mL} \mathrm{~L}^{-1}$, água destilada, solução de $\mathrm{HCl} 5 \%$, água destilada e finalmente em água deionizada, sendo, a seguir, colocados sobre papel absorvente para eliminar o excesso de umidade. Essas amostras foram colocadas em bandejas e permaneceram em estufa com circulação forçada de ar, com temperatura entre 75 e $85^{\circ} \mathrm{C}$, durante 10 dias, para a obtenção da massa da matéria seca dos cachos. A porcentagem de massa da matéria seca do cacho foi obtida pela expressão:

$$
\% \text { MS cacho }=\frac{\text { MS (engaços }+ \text { bagas })}{\text { MF (engaços }+ \text { bagas })} \times 100 .
$$

Onde: $\% \mathrm{MS}$ cacho $=$ percentagem da massa de matéria seca do cacho;

MF (engaços + bagas $)=$ massa da matéria fresca total dos engaços e das bagas;

MS (engaços + bagas $)=$ massa da matéria seca total dos engaços e das bagas após a secagem.

Após a pesagem da matéria seca dos cachos, realizou-se análise química para determinar os teores de macro e micronutrientes segundo metodologia descrita por Malavolta et al. (1997). A partir dos teores de nutrientes contidos nos cachos de uva, estimou-se o acúmulo de nutrientes para cada tonelada de uva, utilizando a equação:

Acúmulo de macronutriente $\left(\mathrm{g} \mathrm{ton}^{-1} \mathrm{uva}\right)=\frac{\% \mathrm{MS} \text { cacho } \times 1000 \times \mathrm{T}}{100}$
Acúmulo de micronutriente $\left(\mathrm{mg}^{-1}\right.$ ton uva $)=\frac{\% \mathrm{MS} \text { cacho } \mathrm{x} 1000 \times \mathrm{T}}{100}$

Onde: $\% \mathrm{MS}=$ percentagem de massa da matéria seca do cacho; $\mathrm{T}=$ teores de macro ou micronutriente no cacho.

Os 40 vinhedos amostrados foram agrupados em função do porta-enxerto utilizado, totalizando 20 vinhedos por portaenxerto, representados pelo 'IAC 766' e 'Ripária do Traviú'. Para analisar o efeito dos porta-exertos nas variáveis analisadas, empregou-se teste $t$, utilizando-se do programa SAS.

\section{RESULTADOS E DISCUSSÃO}

Verificou-se que a produtividade, número de cachos, número de ramos produtivos por planta e duração do ciclo da videira 'Niagara Rosada' enxertada sobre os porta-enxertos 'IAC 766' e 'Ripária do Traviú' foram semelhantes, não havendo diferença significativa (Tabela 1). Devido às parcelas experimentais não serem homogêneas, o alto coeficiente de variação verificado na produtividade pode justificar a ausência de diferença significativa. Cabe ressaltar que a diferença observada na produção de $2.000 \mathrm{~kg} \mathrm{ha}^{-1}$ ou $0,4 \mathrm{~kg} \mathrm{planta}^{-1}$, entre as médias dos porta-enxertos, pode ser considerada representativa para os produtores, pois equivale a mais 350 caixas de $6 \mathrm{~kg}$ de uva a mais por hectare. Pauletto et al. (2001a), Alvarenga et al. (2002) e Terra et al. (2003) também não obtiveram nos porta-enxertos 'IAC 766' e 'Ripária do Traviú' diferenças significativas quanto à produtividade e ao número de cachos. No entanto, a produtividade por planta obtida por esses autores foi superior às médias dos 40 vinhedos aqui amostrados. Quanto ao número total de cachos, os resultados obtidos foram semelhantes aos encontrados por Terra et al. (2003) e menores que os de Pauletto et al. (2001a). Quanto à média da duração do ciclo, os dois porta-enxertos tiveram comportamentos semelhantes, sendo que os valores obtidos concordam com os verificados por Pedro Júnior et al. (1993). O número de ramos produtivos também não foi influenciado pelo porta-enxerto.

Em relação às características físicas dos cachos e bagas da videira 'Niagara Rosada', os valores médios da massa da matéria fresca e seca, comprimento e largura dos cachos foram de, respectivamente, $209 \mathrm{~g}, 13,7 \mathrm{~g}, 12 \mathrm{~cm}$ e $6,8 \mathrm{~cm}$; da massa da matéria fresca, comprimento e largura das bagas e diâmetro do pedicelo de, respectivamente, 4,3g, 19,9mm, 18,2mm e 3,2mm, não havendo diferenças significativas entre os porta-enxertos (Tabela 2). Pauletto et al. (2001b) também obtiveram resultados semelhantes com os mesmos porta-enxertos, para os dados de comprimento, largura e massa fresca dos cachos e bagas, sendo semelhantes os valores obtidos . Observou-se que a massa da matéria fresca média dos cachos obtida nas amostras dos vinhedos apresentou valores de 209,1g, e das bagas de 4,3g, semelhantes aos descritos por Camargo (1998) e Pommer et al. (2003).

Os resultados médios da análise química do solo dos vinhedos selecionados encontram-se na Tabela 3. Em relação aos teores foliares de nutrientesmacro e micronutrientes, os resultados médios são apresentados na Tabela 4.

Quanto ao acúmulo de nutrientes pelos cachos, constatouse que, com o porta-enxerto 'Ripária do Traviú', houve maior acúmulo de fósforo, enxofre, ferro e zinco, e menor de manganês (Tabela 5). Em ambos os porta-enxertos, a cultivar Niagara Rosada apresentou a seguinte escala de acúmulo de nutrientes em ordem decrescente: $\mathrm{K}>\mathrm{N}>\mathrm{P}>\mathrm{Ca}>\mathrm{S}>\mathrm{Mg}>\mathrm{B}>\mathrm{Fe}>\mathrm{Mn}>\mathrm{Cu}>\mathrm{Zn}$. Esses resultados concordam, em parte, com os obtidos por Dechen (1979) e Hiroce et al. (1979), que obtiveram, respectivamente, as seguintes ordens: $\mathrm{K}>\mathrm{N}>\mathrm{P}>\mathrm{Ca}>\mathrm{S}>\mathrm{Mg}>\mathrm{Mn}>\mathrm{Fe}>\mathrm{B}>\mathrm{Zn}>\mathrm{Cu}$ e $\mathrm{K}>\mathrm{N}>\mathrm{P}>\mathrm{S}>$ $\mathrm{Ca}=\mathrm{Mg}>\mathrm{Cl}>\mathrm{Fe}>\mathrm{Mn}>\mathrm{B}>\mathrm{Cu}>\mathrm{Zn}>\mathrm{Mo}$. Verificou-se que a seqüência de acúmulo de macronutrientes foi bastante semelhante, havendo maior diferença no caso dos micronutrientes. Tal diferença deve- 
se, possivelmente, às contaminações com adubos foliares e defensivos agrícolas, dificilmente removidos na lavagem das amostras para análise e pela variação na absorção entre portaenxertos.

Considerando-se uma produtividade de $20.000 \mathrm{~kg}$ de uva ha $^{-1}$, obtém-se, na média dos porta-enxertos, um acúmulo de nutrientes pelos cachos de 'Niagara Rosada' de 27,8; 4,0; 39,6; 2,1; 1,1 e 1,3kg, de N, P, K, Ca, Mg e S, respectivamente, e de 73; $19 ; 50 ; 30$ e $8 \mathrm{~g}$ de $\mathrm{B}, \mathrm{Cu}, \mathrm{Fe}, \mathrm{Mn}$ e $\mathrm{Zn}$, respectivamente. Convertendo as quantidades de $\mathrm{P}$ e $\mathrm{K}$ para $\mathrm{P}_{2} \mathrm{O} 5$ e $\mathrm{K}_{2} \mathrm{O}$, obtém-se um acúmulo pelos cachos de uva de 9,2 e $47,7 \mathrm{~kg} \mathrm{ha}^{-1}$, respectivamente, de $\mathrm{P}_{2} \mathrm{O} 5$ e $\mathrm{K}_{2} \mathrm{O}$.

Segundo Terra (2003), para uma produtividade esperada de $20.000 \mathrm{~kg} \mathrm{ha}^{-1}$, em solos com teores elevados de P e K disponíveis, como os que prevalecem nos vinhedos em estudo, recomenda-se aplicar anualmente $100 \mathrm{~kg} \mathrm{ha}^{-1}$ de $\mathrm{N}$ e de $\mathrm{P}_{2} \mathrm{O} 5$, e 75 $\mathrm{kg} \mathrm{ha}^{-1}$ de $\mathrm{K}_{2} \mathrm{O}$ como adubação de produção. Comparando-se essa recomendação com as estimativas obtidas neste trabalho (Figura 1), observou-se que, aproximadamente, $28 \%$ do N, $9 \%$ do $\mathrm{P}$ e $63 \%$ do $\mathrm{K}$ aplicados são acumulados e, posteriormente, extraídos com a colheita dos cachos, ratificando a importância da adubação de manutenção para a sustentabilidade das videiras.

Quanto aos micronutrientes, destacou-se o acúmulo de boro pelos cachos que, na média dos porta-enxertos, atingiu 3,6g t ${ }^{1}$.

TABELA 1- Resultados médios e análise de variância da produtividade, do número de cachos, número de ramos produtivos e da duração do ciclo em 40 vinhedos de 'Niagara Rosada', enxertada nos porta-enxertos 'IAC 766' e 'Ripária do Traviú'.

\begin{tabular}{cccccc} 
& \multicolumn{2}{c}{ Produtividade } & \multicolumn{2}{c}{ Número planta -1 } & Duração do ciclo \\
\hline Porta-enxerto & $\left(\mathbf{K g ~ h a}^{-1}\right)$ & $\left.\mathbf{K g ~ p l a n t a ~}^{-1}\right)$ & Cachos & Ramos & (dias) \\
\hline 'IAC 766' & $12.100 \mathrm{~A}$ & $2,0 \mathrm{~A}$ & $13,7 \mathrm{~A}$ & $9,5 \mathrm{~A}$ & $135,7 \mathrm{~A}$ \\
Ripária do Traviú' & $10.100 \mathrm{~A}$ & $1,6 \mathrm{~A}$ & $11,9 \mathrm{~A}$ & $8,3 \mathrm{~A}$ & $132,8 \mathrm{~A}$ \\
\hline Média & 11.100 & 1,8 & 12,8 & 8,9 & 134,2 \\
\hline CV\% & 49 & 53 & 33 & 24 & 3 \\
DMS & 3520 & 0,62 & 2,74 & 1,42 & 3,04 \\
Erro padrão & 1,23 & 0,22 & 0,96 & 0,50 & 1,06 \\
Valor de F & $1,29^{\mathrm{NS}}$ & $1,82^{\mathrm{NS}}$ & $1,67^{\mathrm{NS}}$ & $3,13^{\mathrm{NS}}$ & $3,60^{\mathrm{NS}}$ \\
\hline Médias seguidas de letras diferentes na coluna diferem entre si, ao nível de $5 \%$, pelo teste t.
\end{tabular}

TABELA 2 - Resultados médios e análise de variância da massa da matéria fresca (MF) e seca (MS), comprimento, largura dos cachos, massa da matéria fresca, comprimento e largura de bagas e diâmetro do pedicelo de cachos, em 40 vinhedos de 'Niagara Rosada', enxertada nos porta-enxertos 'IAC 766' e no 'Ripária do Traviú'.

\begin{tabular}{|c|c|c|c|c|c|c|c|c|}
\hline \multirow[b]{2}{*}{ Porta-enxerto } & \multicolumn{4}{|c|}{ СACHOS } & \multicolumn{3}{|c|}{ BAGAS } & \multirow{2}{*}{$\begin{array}{c}\text { Diâmetro } \\
\text { Pedicelo } \\
(\mathrm{mm})\end{array}$} \\
\hline & $\begin{array}{r}\text { MF } \\
(\mathrm{g})\end{array}$ & $\begin{array}{l}\text { MF } \\
(\mathrm{g})\end{array}$ & $\begin{array}{c}\text { Comprimento } \\
(\mathrm{cm})\end{array}$ & $\begin{array}{c}\text { Largura } \\
(\mathrm{cm})\end{array}$ & $\begin{array}{r}\text { MF } \\
(\mathrm{g})\end{array}$ & $\begin{array}{c}\text { Comprimento } \\
(\mathrm{mm})\end{array}$ & $\begin{array}{c}\text { Largura } \\
(\mathrm{mm})\end{array}$ & \\
\hline 'IAC 766' & $215,3 \mathrm{~A}$ & $13,4 \mathrm{~A}$ & $12,1 \mathrm{~A}$ & $6,9 \mathrm{~A}$ & $4,2 \mathrm{~A}$ & $19,8 \mathrm{~A}$ & $18,0 \mathrm{~A}$ & $3,0 \mathrm{~A}$ \\
\hline 'Ripária do Traviú' & $202,9 \mathrm{~A}$ & $14,0 \mathrm{~A}$ & $11,9 \mathrm{~A}$ & $6,7 \mathrm{~A}$ & $4,3 \mathrm{~A}$ & $19,9 \mathrm{~A}$ & $18,3 \mathrm{~A}$ & $3,3 \mathrm{~A}$ \\
\hline Média & 209,1 & 13,7 & 12,0 & 6,8 & 4,3 & 19,9 & 18,2 & 3,2 \\
\hline $\mathrm{CV} \%$ & 11 & 13 & 6 & 7 & 7 & 2 & 3 & 19 \\
\hline DMS & 15,73 & 1,17 & 0,53 & 0,31 & 0,20 & 0,37 & 0,37 & 0,40 \\
\hline Erro padrão & 5,49 & 0,41 & 0,18 & 0,11 & 0,07 & 0,13 & 0,13 & 0,14 \\
\hline Valor de F & $2,55^{\mathrm{NS}}$ & $1,28^{\mathrm{VS}}$ & $0,60^{\mathrm{NS}}$ & $1,25^{\mathrm{NS}}$ & $0,19^{\mathrm{NS}}$ & $0,08^{\mathrm{NS}}$ & $2,08^{\mathrm{NS}}$ & $1,56^{\mathrm{NS}}$ \\
\hline
\end{tabular}

Médias seguidas de letras diferentes na coluna diferem entre si, ao nível de $5 \%$, pelo teste t.
TABELA 3 - Dados médios das análises de solos em amostras realizadas a $0-20 \mathrm{~cm}$ de profundidade, em 40 vinhedos de 'Niagara Rosada'.

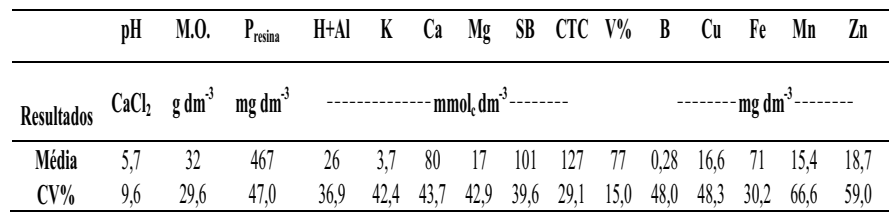

TABELA 4 - Resultados médios dos teores de macro e micronutrientes nas amostras de folha completa realizadas durante o pleno florescimento da videira, em 40 vinhedos de 'Niagara Rosada', enxertada nos porta-enxertos 'IAC 766' e no 'Ripária do Traviú'.

\begin{tabular}{|c|c|c|c|c|c|c|c|c|c|c|c|}
\hline & $N$ & $P$ & K & $\mathrm{Ca}$ & Mg & $S$ & B & $\mathrm{Cu}$ & $\mathrm{Fe}$ & $\mathrm{Mn}$ & $\mathrm{Zn}$ \\
\hline Resultados & \multicolumn{6}{|c|}{$\mathrm{g} \mathrm{kg}^{-1}$} & \multicolumn{5}{|c|}{$m g \mathrm{~kg}^{-1}$} \\
\hline Média & 38 & 4,3 & 19 & 9 & 2,3 & 2,6 & 42 & 19 & 95 & 103 & 22 \\
\hline $\mathrm{CV} \%$ & 5,19 & 24,02 & 23,80 & 22.91 & 26,51 & 13,97 & 36,41 & 37,95 & 15,72 & 32,69 & 28.26 \\
\hline
\end{tabular}

Médias seguidas de letras diferentes na coluna diferem entre si, ao nível de $5 \%$, pelo teste $\mathrm{t}$

TABELA 5 - Resultados médios e análise de variância da acúmulo de macronutrientes $\left(\mathrm{g}_{\text {ton }} \mathrm{uva}^{-1}\right)$ e micronutrientes ( $m g$ ton uva $^{-1}$ ) na colheita de uva 'Niagara Rosada', enxertada nos porta-enxertos 'IAC 766' e no 'Ripária do Traviú', em amostra em 40 vinhedos.

\begin{tabular}{|c|c|c|c|c|c|c|c|c|c|c|c|}
\hline \multirow[b]{2}{*}{ Porta-enxerto } & $\mathrm{N}$ & $P$ & $\mathrm{~K}$ & $\mathrm{Ca}$ & $\mathrm{Mg}$ & S & B & $\mathrm{Cu}$ & $\mathrm{Fe}$ & $\mathrm{Mn}$ & $\mathrm{Zn}$ \\
\hline & \multicolumn{6}{|c|}{$\mathrm{g} \operatorname{ton}^{-1} \mathrm{uva}^{-1}$} & \multicolumn{5}{|c|}{$\mathrm{mg} \mathrm{ton}^{-1} \mathrm{uva}^{-1}$} \\
\hline 'IAC 766' & $1351 \mathrm{~A}$ & $186 \mathrm{~B}$ & 1940A & $102 \mathrm{~A}$ & $54 \mathrm{~A}$ & $60 \mathrm{~B}$ & $3736 \mathrm{~A}$ & $936 \mathrm{~A}$ & $2305 \mathrm{~B}$ & $1743 \mathrm{~A}$ & $341 \mathrm{~B}$ \\
\hline 'Ripária do Traviú' & $1430 \mathrm{~A}$ & $218 \mathrm{~A}$ & $2017 \mathrm{~A}$ & $110 \mathrm{~A}$ & $61 \mathrm{~A}$ & $66 \mathrm{~A}$ & $3557 \mathrm{~A}$ & $958 \mathrm{~A}$ & $2699 \mathrm{~A}$ & $1246 \mathrm{~B}$ & $473 \mathrm{~A}$ \\
\hline Média & 1390 & 202 & 1978 & 106 & 57 & 63 & 3646 & 947 & 2502 & 1495 & 407 \\
\hline $\mathrm{CV} \%$ & 10 & 17 & 13 & 16 & 41 & 13 & 25 & 31 & 24 & 47 & 35 \\
\hline DMS & 92,0 & 23,1 & 173,6 & 11,0 & 15,2 & 5,3 & 596,6 & 189,1 & 387,0 & 456,1 & 92,1 \\
\hline Erro padrão & 32,1 & 8,1 & 60,6 & 3,9 & 5,3 & 1,8 & 208,4 & 66,1 & 135,2 & 159,3 & 32,2 \\
\hline Valor de $\mathrm{F}$ & $3,04^{\sqrt{5}}$ & $7,81^{* *}$ & $0,81^{\mathrm{NS}}$ & $2,42^{\mathrm{NS}}$ & $0,93^{\mathrm{NS}}$ & $5,72^{*}$ & $0,37^{\mathrm{NS}}$ & $0,1^{\mathrm{SS}}$ & $4,25^{*}$ & $4,87 *$ & $8,41 * *$ \\
\hline
\end{tabular}

Médias seguidas de letras diferentes na coluna diferem entre si, ao nível de $5 \%$, pelo teste $\mathrm{t}$.

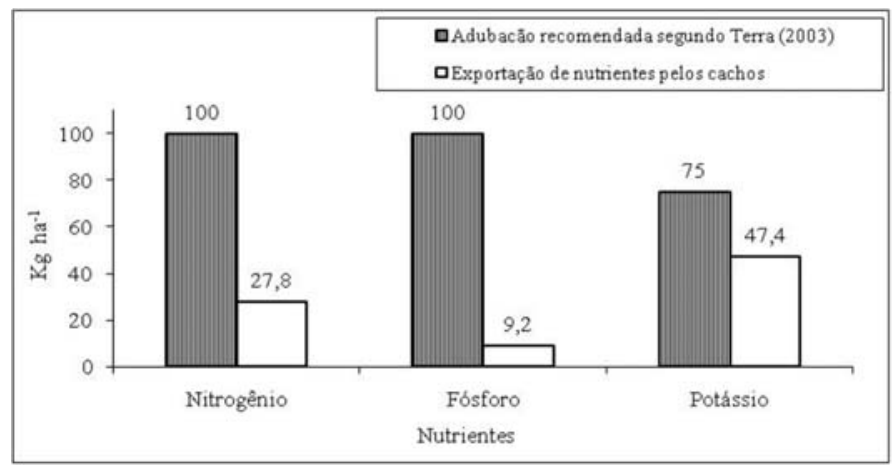

FIGURA 1- Quantidade de nitrogênio, fósforo e potássio recomendada por Terra (2003) e acumulada pelos cachos de videira 'Niagara Rosada' em vinhedos amostrados nas regiões de Jundiaí e Louveira-SP. 


\section{CONCLUSÃO}

Constatou-se um comportamento semelhante entre os porta-enxertos quanto à produtividade, características físicas dos cachos, número de cachos, número de ramos produtivos e duração do ciclo, havendo no entanto diferenças nos teores de nutrientes nas folhas e no acúmulo de nutrientes pelos cachos. No porta-enxerto 'Ripária do Traviú', houve maior acúmulo pelos cachos de fósforo, enxofre, ferro e zinco, e menor acúmulo de manganês, evidenciando absorção diferencial de nutrientes em função do porta-exerto. Em ambos os porta-enxertos, a cultivar Niagara Rosada apresentou a seguinte escala de acúmulo de nutrientes em ordem decrescente: $\quad \mathrm{K}>\mathrm{N}>\mathrm{P}>\mathrm{Ca}>\mathrm{S}>\mathrm{Mg}>\mathrm{B}>\mathrm{Fe}>\mathrm{Mn}>\mathrm{Cu}>\mathrm{Zn} . \quad A$ proporção de $\mathrm{N}, \mathrm{P}$ e $\mathrm{K}$ que é extraída pelos cachos em relação à recomendação de adubação para videira, reforça a importância da adubação de manutenção realizada anualmente nos vinhedos.

\section{REFERÊNCIAS}

ALBUQUERQUE, T. C. S. Uva para exportação: aspectos técnicos da produção. Brasília: Embrapa/Centro Nacional de Pesquisa de Mandioca e Fruticultura, 1996. 53 p. (Frupex).

ALVARENGA,A.A., REGINA, M.A., FRÁGUAS, J.C, CHALFUN, N.N.J., SILVA, A.L. Influência do porta-enxerto sobre o crescimento e produção da cultivar de videira Niagara Rosada (Vitis labrusca L. x Vitis viniferea L.), em condições de solo ácido. Ciência e Agrotecnologia, Lavras, p. 1459-1464, dez., 2002. Edição especial

BRAGA, F. G. Cultura da uva Niagara Rosada. São Paulo: Nobel, $1988.66 \mathrm{p}$.

CAMARGO, U.A. Cultivares para a viticultura tropical no Brasil. Informe Agropecuário, Belo Horizonte, v. 19, n. 194, p. 15-19, 1998.

DECHEN, A. R. Acúmulo de nutritentes pela videira (Vitis labrusca L. $\mathrm{x}$ Vitis vinifera L.) cv. 'Niágara Rosada', durante um ciclo vegetativo. 1979. 133 f. Dissertação (Mestrado em Agronomia) Escola Superior de Agricultura "Luiz de Queiroz", Universidade de São Paulo, Piracicaba, 1979.

FRÁGUAS, J. C.; SILVA, D. J. Nutrição e adubação da videira em regiões Tropicais. Informe Agropecuário, Belo Horizonte, v. 19, n. 194, p. 70-75, 1998.

GHILARDI, A. A.; MAIA, M. L. Tecnologia, custo de produção e rentabilidade do cultivo de uva Niagara no Estado de São Paulo. Informações econômicas, São Paulo, v. 31, n. 12, p. 48-64, 2001.

HIROCE, R.; GALLO, J.R.; BATAGLIA, O.C.; FURLANI, P.R.;
FURLANI, A.M.C. Composição mineral e exportação de nutrientes pelas colheitas de frutos tropicais e temperados. In: CONGRESSO BRASILEIRO DE FRUTICULTURA, 5., 1979, Pelotas. Anais... Pelotas: Sociedade Brasileira de Fruticultura, 1979. p. 179-189.

INSTITUTO DE ECONOMIAAGRÍCOLA. Produção e número de plantas de videira no Estado de São Paulo: Dezembro de 2000. Disponível em: <http:// www.iea.sp.gov.br.>. Acesso em: 12 set. 2006.

MALAVOLTA, E.; VITTI, G. C.; OLIVEIRA, S. A. Avaliação do estado nutricional de plantas: princípios e aplicações. 2.ed. Piracicaba: Potafos, 1997. 319 p.

PAULETTO, D.; MORÃO FILHO, F.A.A.; KLUGE, R.A.; SCARPARE FILHO, J.A. Produção e vigor da videira 'Niagara Rosda'relacionados com o porta-enxerto. Pesquisa Agropecuária Brasileira, Brasília, v. 36, n. 1, p. 115-121, jan. 2001a.

PAULETTO, D.; MORÃO FILHO, F.A.A.; KLUGE, R.A.; SCARPARE FILHO, J.A. Efeito do porta-enxerto na qualidade do cacho da videira 'Niagara Rosada'. Pesquisa Agropecuária Brasileira, Brasília, v. 36, n. 7, p. 935-939, jul. 2001 b.

PEDRO JÚNIOR., M.J.; SENTELHAS, P.C; POMMER, C.V.; MARTINS, F.P.; GALLO, P.B.; SANTOS, R.B.; BOVI, V; SABINO, J.C. Caracterização fenológica da videira 'Niagara Rosada' em diferentes regiões paulistas. Bragantia, Campinas, v. 52, n. 2, p. 161-168, 1993.

POMMER, C.V.; TERRA, M.M.; PIRES, E.R.P. Cultivares, melhoramento e fisiologia. In: POMMER, C.V. Uva: tecnologia de produção, pós-colheita, mercado. Porto Alegre: Cinco Continentes, 2003. cap. 4, p. 109-294.

RAIJ, B. van; ANDRADE, J.C.; CANTARELLA, H.; QUAGGIO, J.A. Análise química para avaliação da fertilidade de solos tropicais. Campinas: Instituto Agronômico, 2001, 285p.

SANTOS NETO, J. R. A. A cultura da videira. Campinas: Instituto Agronômico, 1973. (Boletim Técnico, 203)

TECCHIO, M.A. Levantamento nutricional e diagnóstico agronômico da videira 'Niagara Rosada' em Jundiaí e LouveiraSP. 2005. 109 f. Tese (Doutorado em Horticultura) - Faculdade de Ciências Agronômicas, Universidade Estadual Paulista, Botucatu, 2005.

TERRA, M. M. Nutrição, calagem e adubação. In: POMMER, C.V. Uva: tecnologia de produção, pós-colheita, mercado. Porto Alegre: Cinco Continentes, 2003. cap. 7, p. 405-476. 